\title{
Working Politically: Combining Socio-Legal Tools to Study Experiences of Law
}

\author{
Jess Mant*(1)
}

(Received 03 September 2020; accepted 13 September 2020)

\begin{abstract}
This Article provides a novel insight into how early-career scholars in the UK may combine different theoretical tools in their research, and the implications that this may have for the socio-legal discipline. This Article draws upon the author's experience of combining theoretical tools from different schools of thought: Feminist legal theory, Bourdieusian theory, and Actor Network Theory, within the context of recent research into experiences of those representing themselves in family court hearings in England and Wales. Combining these theories for the first time, this Article explores the difficulties, tensions, and benefits of combining tools within socio-legal research and reflects upon the influence of the pedagogical and institutional resources that characterize the socio-legal research environment in the UK. This Article argues that the task of combining different tools provides scholars with the opportunity to work politically, because the process of reconciling tensions between different approaches requires researchers to reflect upon the worldviews that underpin their selected theories. In this sense, it argues that combining different theories within socio-legal research is a political activity, because researchers are required to reflect not only on how theoretical choices may contest, expand, or develop dominant assumptions that characterize socio-legal scholarly traditions.
\end{abstract}

Keywords: Socio-Legal; legal theory; legal aid; inequality; England and Wales; methodology; feminism; Actor-Network Theory; Bourdieusian theory

\section{A. Introduction}

The discipline of "socio-legal" encompasses a broad range of scholarship which distinguishes itself from doctrinal approaches to law. Notwithstanding this breadth, the discipline is far from fragmented in the UK. Rather, in addition to using analytical tools from a variety of other disciplines beyond law—and often beyond sociology—pioneering scholars have also invested decades into organizing themselves under the banner of socio-legal. ${ }^{1}$ Particularly within the UK, this innovation has resulted in a fertile research environment for early-career scholars, who frequently benefit from socio-legal pedagogical influences within their legal education, institutional support for socio-legal doctoral projects, as well as the systematic supervision and guidance of more senior scholars who continue to play an important role in consolidating and pushing the boundaries of the discipline. As a result, the emerging generation of socio-legal researchers in the UK are less likely to face barriers in establishing the value of using interdisciplinary approaches to study the complex and situated role of law within society. However, they are instead faced with a different

\footnotetext{
${ }^{\star}$ Jess Mant is a Lecturer in Law at Cardiff University, UK. Dr. Mant specializes in family law and issues regarding access to legal aid. Email: MantJ@Cardiff.ac.uk. The author is grateful to Katie Richards, Steve Smith, Pauline Roberts, Rachel Cahill O'Callaghan, and the editors of this Special Issue for their feedback on earlier drafts of this work.

${ }^{1}$ See generally Sally Wheeler \& Phil Thomas, Socio-Legal Studies, in LAW(s) FuTURES 267 (David Hayton ed., 2000). unrestricted re-use, distribution, and reproduction in any medium, provided the original work is properly cited.
} 
challenge-important choices about how to use the tools and resources available to them from the different schools of thought which fall under this banner of socio-legal studies. These choices have important implications for which scholarly traditions are strengthened and reiterated, and how the discipline is to continue to develop.

The purpose of this Article is to provide an insight into how early-career socio-legal researchers may build upon the work of previous generations by combining multiple socio-legal tools from different schools of thought. It contributes a reflective account of how it was possible to draw together multiple socio-legal tools within my own recent research project undertaken in the UK. The aim of this research was to provide a deeper understanding of what it is like for people who are representing themselves as Litigants in Person in court in England and Wales, following a major withdrawal of legal aid for private family law cases by the UK government. ${ }^{2}$ As part of this project, I conducted interviews with Litigants in Person to find out about the difficulties they experienced following this reform. ${ }^{3}$ In doing so, I required conceptual resources that enabled me to do two things. First, I needed to understand how structural inequalities in society may shape the experiences that people in England and Wales have of using law. Second, I needed to reflect on how the culture and procedure of the legal system in England and Wales may itself facilitate or exacerbate experiences of disadvantage. To these ends, I devised a unique theoretical framework by drawing together three different approaches, each originating from distinct schools of thought which have, to varying degrees, been used by scholars working within the socio-legal discipline in the UK but have never before been drawn together: Feminist legal theory, Pierre Bourdieu's theory of social class, and Actor-Network Theory (ANT).

This Article will begin by outlining the usefulness of these approaches for understanding experiences of inequality and disadvantage and discussing the challenges inherent in the task of combining these approaches. First, I explain that feminist legal theory is a useful resource for appreciating how law is often formulated in a way that is blind to marginalized experiences, and how multiple structures of inequality may overlap in order to produce unique and intersectional experiences of law. Specifically, it encourages researchers to ask the "woman question," which means to ask questions aimed at exposing these hidden, diverse, and intersectional perspectives of law. Second, I argue that this approach can be reinforced with Bourdieusian theory, which specifically addresses issues of class, systems, and processes. This particular theory provides three key concepts — capital, field, and habitus — which are useful for tracing those structural inequalities that feminist theory demonstrates are otherwise absent from law and policy. Combining these two theories enabled me to use Bourdieusian concepts in an intersectional way, which meant both extending the scope of my analysis to incorporate understandings of class, as well as tracing multiple and overlapping structural forms of inequality which intersect to produce unique experiences of disadvantage.

Building upon these two combined approaches, I then discuss the value of drawing upon the third approach of ANT. While the first two approaches provide useful ways to think through the structural context of difference and inequality, it is useful to go further in order to understand how these inequalities may manifest as disadvantage within the specific context of the family court in England and Wales. ANT, therefore, provides a pragmatic tool for examining the material ways in which Litigants in Person may experience disadvantage within the legal system itself. This involves tracing the detail of the interactions that Litigants in Person have with other people, objects, and environments in the legal system. As an approach, ANT has been criticized within socio-legal studies for being problematically anti-structural, but at the same time, it is nevertheless also distinctly anti-doctrinal, because it requires researchers to view law as only one part of a complex

\footnotetext{
${ }^{2}$ Under the Legal Aid, Sentencing and Punishment of Offenders Act 2012, state-funded legal aid for advice and representation has been almost entirely removed from private family law cases in England and Wales.

${ }^{3}$ For more detail on this research project and issue within England and Wales more generally, see Jessica Mant, Litigants' Experiences of the Post-LASPO Family Court: Key Findings from Recent Research, 3 FAM. L.J. 300 (2019).
} 
network of actors, instead of endowing law with symbolic significance. I will argue that ANT can be used in a way that complements the structural tools drawn from the other two approaches, because it enabled me to also explore the specific and material practices through which inequalities and difference manifest in disadvantage within the legal system in England and Wales.

This Article will then discuss the tensions that underpinned the research process as a result of the decision to use these approaches together. Here, it will argue that the task of working through these tensions is a political activity which holds important consequences for the socio-legal discipline. Different theories, particularly those which emerge from different schools of thought, are underpinned by different ontological and epistemological assumptions. As such, it is generally accepted that a researcher's choice of theory shapes their understanding of the research problem. However, when combining multiple theories, researchers are forced to consider the assumptions that underpin each of their selected theories, and how they contest each other. They must then decide which of these assumptions to prioritize and which to reject in order to reconcile their theories into a theoretical frame that can be used within their research. These decisions are political because they involve choosing which theoretical assumptions and worldviews underpin their research. Importantly, these decisions may also be political because scholars may make these decisions in a way that actively resists dominant assumptions and worldviews. On the basis of this, this Article will argue that the task of combining different theories involves an opportunity to work politically, which means to reflect not only upon how theoretical choices affect one's own research outcomes, but also upon how these choices may contest, expand, or develop the dominant assumptions and worldviews that characterize socio-legal scholarly traditions. This degree of reflexivity is imperative among early career scholars who choose to combine multiple theories because the work of these scholars will shape the future assumptions and worldviews that characterize the socio-legal discipline.

\section{B. Feminist Legal Theory}

As a dominant school of thought within socio-legal studies, feminist legal scholarship encompasses a broad and diverse literature which offers a range of insights into how law can operate to exclude and marginalize women, facilitate and contribute to their experiences of wider inequalities, and omit their subjectivities whilst presenting male subjectivities as objective, legitimate, or simply as common sense. A rich history of feminist perspectives has been useful for achieving a great deal in terms of substantive legal and political reform, as well as informing how scholars think about the basis upon which such claims should be formulated. ${ }^{4}$ These have ranged from liberal claims for formal equality within law, radical calls for more focused attention on the relationship between sexual difference and oppression, to constructivist understandings of how men and women are constructed differently on the basis of their gender, and the specific ways in which law unevenly reinforces and reproduces these constructions. ${ }^{5}$

In all forms, feminism seeks to reveal and develop an understanding of the conditions of women's lives and suggest how these conditions may be improved-either by undertaking a broader critique of the structures that produce those conditions or advocating specific reforms within those structures. ${ }^{6}$ Importantly, both tasks involve telling stories that account for the diverse experiences of women - paying careful attention to different perspectives, definitions, and meanings which have otherwise been omitted or silenced within law. By rendering the concerns of women both visible and valuable, feminist theory provides a resource for exposing how law is both actively and passively implicated in experiences of inequality and disadvantage. For example, early

\footnotetext{
${ }^{4}$ Hilarie Barnett, Introduction to Feminist Jurisprudence 8 (1998).

${ }^{5} I d$. at $5-8$.

${ }^{6}$ Jo Bridgeman \& Daniel Monk, Introduction: Reflections on the Relationship Between Feminism and Child Law, in FEMINIST Perspectives on Child Law 1, 7 (Jo Bridgeman \& Daniel Monk eds., 2000).
} 
feminist legal scholarship has been key in campaigning for equality within law, and against the explicit and overt ways in which law may treat men and women differently. However, more recently feminists have moved beyond calls for formal equality in order to expose the more subtle ways in which law omits the concerns and realities of women's lives and is often complicit in conditions of inequality. ${ }^{7}$

For instance, while statutory provision may now give equality between men and women in terms of legal entitlements, feminists have argued that law nevertheless frequently fails to acknowledge the important ways in which the conditions of their lives differ, or recognize that different treatment may sometimes be required in order to achieve substantive equality. ${ }^{8}$ Within the context of my research on Litigants in Person, for instance, it was possible to use a feminist lens to expose the distinctly gendered ways in which parents experienced the court process. Disproportionately, mothers had fewer economic resources with which to seek legal advice and representation in the absence of legal aid and are also overwhelmingly more likely to be contending with issues like domestic abuse within the court process. As such, my findings reiterated those of earlier projects in suggesting that the court process is not designed in a way that explicitly acknowledges the gendered reality of family disputes. ${ }^{9}$

Across many jurisdictions, scholars, activists, and lawyers have undertaken the task of rewriting judgments from a feminist perspective in order to show that even if law does not discriminate between men and women, its failure to incorporate the understandings, experiences, and perceptions of women within its legal definitions and rules is a cause of harm in and of itself. ${ }^{10}$ As these projects show, women experience inequality in multiple ways-both by way of gender-specific harms, and also by way of law's failure to recognize and respond to them. ${ }^{11}$ As explored by Ulrike Schultz earlier in this Special Issue, law across jurisdictions tends to be designed around the idea of a "non-gendered, non-differentiated legal subject," and this has important consequences for the role that law can play in ignoring, facilitating, and reiterating the material inequalities that women experience within society. ${ }^{12}$

As such, a feminist approach advocates expanding the lens of critique to include other structures and institutions which interact with law, such as the family, the labor market, or the tax and benefit system. Within different countries, cultures, and political contexts, a feminist analysis will therefore inevitably vary, but a common goal is to study law as one of several forces that form the backdrop to a society that is structured in a way that omits the concerns and realities of women's lives. ${ }^{13}$ Using feminism to expose these hidden perspectives involves asking what is often referred to as the "woman question." In practice, this involves asking several different questions, such as: What kinds of assumptions, descriptions, or assertions underpin legal definitions and understandings? Further, how do these understandings compare to the lived realities and experiences of women? By asking

\footnotetext{
${ }^{7}$ Alison Diduck \& Katherine O’Donovan, Feminism and Families: Plus ca change?, in Feminist PersPeCtives ON FAMILY LAW, supra note 6, at 1, 2-5; JoAnne ConAghan, LAW AND GENDER 103 (2013).

${ }^{8}$ Diduck \& O'Donovan, supra note 7 , at 9.

${ }^{9}$ Mant, supra note 3. See also Liz Trinder et al., Litigants in Person in Private Family Law Cases, in MiNisTRY OF JUSTICE ANALYTICAL SERIES (2014).

${ }^{10}$ Bridgeman \& Monk, supra note 6, at 7. Feminist judgment projects have been undertaken in Australia, New Zealand, and the United States, as well as all UK jurisdictions. See Rosemary Hunter, Clare McGlynn \& Erica Rackley, Feminist Judgments: From Theory to Practice (2010); Heather Douglas, Francesca Bartlett, Trish luker \& Rosemary Hunter, Australian Feminist Judgments: Righting and Rewriting Law (2014); Kathryn Stanchi, Linda Berger \& Bridget Crawford, Feminist Judgments: Rewritten Opinions of the United States Supreme Court (2016); Máiréad Enright, Julie McCandless \& AOIFe O’Donoghe, Northern/Irish Feminist Judgments: Judges' Troubles and the Gendered Politics of Identity (2017); Sharon Cowan, Chloë Kennedy \& Vanessa Munro, Scottish Feminist Judgments: (Re)Creating Law From the Outside In (2019).

${ }^{11}$ Robin West, Jurisprudence and Gender, 55 U. CHI. L. REV. 1 (1988).

${ }^{12}$ Rosemary Hunter, The Gendered 'Socio' of Socio-Legal Studies, in ExPLORING THE 'Socio' OF SOCIO-LEGAL STUDIES 205 (Feenan Dermott ed., 2013).

${ }^{13}$ Diduck and O'Donovan, supra note 7, at 5; ConAGHan, supra note 7, at 103.
} 
these questions, it is possible to challenge the interests that are at the center of law and demand justification for the inequalities and disadvantages that this disparity perpetuates. ${ }^{14}$

Several feminist legal scholars have emphasized that this visibility is important for women because it raises "collective consciousness" among women who recognize and relate to the experiences that are exposed through this activity. ${ }^{15}$ For example, there are some concerns which are common among women, such as the way in which structures like law operate to define the meaning of concepts like motherhood and mothering. Similarly, in their research into the legal aid system in Australia, Rosemary Hunter and Tracey De Simone found that although eligibility policy did not overtly distinguish between men and women, women were disproportionately disadvantaged by the fact that applications for family legal aid were afforded lower priority than those for legal aid in criminal matters, because the latter cases were presented as objectively more serious. ${ }^{16}$ Consciousness-raising among women is therefore a means through which individual experiences of harm can be translated into collective experiences of oppression, which can in turn be used as an evidence base and an impetus to dismantle systems and structures that perpetuate inequality. ${ }^{17}$ However, while this has obvious value, feminist scholars have drawn attention to the important limitations of research that claims to expose the experiences and perspectives of women, without accommodating the diverse and intersectional ways in which different women experience law.

Modern feminist scholarship, particularly that which is geared towards achieving legal and political reform, is intersectional. Intersectionality is a concept largely attributed to the ground-breaking work of Kimberlé Crenshaw. ${ }^{18}$ It is derived from arguments that mainstream feminist discourse was unable to account for the unique forms of disadvantage that are experienced by women of color, who exist at the intersection between racism and sexism. The idea that multiple forms of oppression or marginalization can intersect and produce specific experiences of disadvantage has been taken up by feminists who seek to avoid producing research which claims to speak for all women. ${ }^{19}$ In doing so, they recognize the value of raising collective consciousness, whilst also challenging the notion that women have a collective set of interests, characteristics, or needs. ${ }^{20}$

In this sense, asking the "woman question" means asking questions that reach beyond issues of gender, and scrutinizing how legal discourse also omits experiences of other inequalities. ${ }^{21}$ Further, rather than someone experiencing multiple forms of disadvantage at once, the metaphor of the intersection allows researchers to appreciate how people can be marginalized as a result of different kinds of disadvantage, which intersect in ways that are situated, particular, and which cannot be untangled from one another. ${ }^{22}$ A feminist approach which is intersectional seeks to expose the complexity of experiences that are omitted from law and legal practice, by telling stories that account for diverse experiences - including but not limited to gender - and resisting the temptation to explore just the aspects of people's lives that the law determines to be relevant or important. ${ }^{23}$

Asking the "woman question," therefore, can broadly be understood as a commitment to constructing a narrative that is not built out of abstract principles but is instead built "from the ground

\footnotetext{
${ }^{14}$ BARNETT, supra note 4 , at 23.

${ }^{15}$ Katherine Bartlett, Feminist Legal Methods, 103 Harv. L. REv. 829, 863-67 (1990).

${ }^{16}$ Rosemary Hunter \& Tracey De Simone, Identifying Disadvantage: Beyond Intersectionality, in INTERSECTIONALITY AND Beyond: LAW, Power AND the Politics of Location 159, 161-62(Emily Grabham et al. eds., 2009).

${ }^{17}$ Bartlett, supra note 15 , at 837.

${ }^{18}$ Kimberlé Crenshaw, Demarginalizing the Intersection of Race and Sex: A Black Feminist Critique of Antidiscrimination Doctrine, Feminist Theory and Antiracist Politics, 1 U. CHI. Legal F. 139 (1989); Kimberlé Crenshaw, Mapping the Margins: Intersectionality, Identity Politics, and Violence Against Women of Color, 43 STAN. L. ReV. 1241 (1991).

${ }^{19}$ See generally Hunter \& De Simone, supra note 16.

${ }^{20}$ Joanne Conaghan, Intersectionality and UK Equality Initiatives, 23 S. AfrICAN J. HUM. RTs. 317 (2007); Emily Grabham, Taxonomies of Inequality: Lawyers, Maps and the Challenge of Hybridity, 15 Soc. \& LEGAL STUD. 5 (2006); BARNETT, supra note 4 , at 7-8, 19-21.

${ }^{21}$ Bartlett, supra note 15 , at 837.

${ }^{22}$ Emily Grabham et al., Introduction to INTERSECTIONALITY AND BEYOND, supra note 16, at 1.

${ }^{23}$ ConAghan, supra note 7 , at $12-14$.
} 
up, out of concrete, specific practices." ${ }^{24}$ However, in producing an account that can expose the complexity of experiences and perspectives, it is important not to lose sight of the structures that facilitate these experiences. A focus on intersectionality has, for some feminists, gone too far towards a "formulaic analysis" of individuals and their identity characteristics, and foregone the task of scrutinizing and challenging structures, institutions, and processes themselves. ${ }^{25}$ For example, understandings of social class are frequently absent from feminist intersectionality scholarship, because class does not function easily as an identity category; intersectional understandings of inequality are focused on how law responds to people's experiences, while class analyses tend to focus on the structured processes by which those experiences are produced and mediated. ${ }^{26}$ A theory of class was, however, of imperative importance within my research, because the accessibility of legal advice and representation has historically been framed by socio-economic inequality, and the disparity between those who can access legal support is now even more stark in light of the removal of legal aid. Within this project, it was therefore useful to reinforce a feminist approach with a theory of social class, which is useful for tracing those structural inequalities that feminist theory demonstrates are otherwise absent from law and policy.

\section{Bourdieusian Theory}

Although Bourdieusian theory is not widely used within socio-legal studies in the UK, Pierre Bourdieu's theory of class is particularly useful for studying experiences of law. ${ }^{27}$ This is because his theory provides three foundational concepts - capital, field, and habitus - which can be used to understand how socio-economic inequality is reproduced through culture. This cultural focus permits an analysis which accounts for both the unequal distribution of resources, as well as the inequalities of recognition and value which characterize structures and institutions such as law. Further, these conceptual tools also enable researchers to explore how unequal arrangements are frequently reiterated through the interpretations of individuals themselves, as they subjectively assess and interpret their own position in relation to others within particular contexts like the legal system. As will be discussed shortly, this cultural dimension has enabled subsequent scholars to develop Bourdieu's theory in order to understand the reproduction of other forms of difference beyond class, such as gender. In this section, I will outline these three concepts before discussing how these can be usefully combined with feminist legal theory in order to highlight how different inequalities may intersect with each other to produce complex experiences of disadvantage that are omitted within law.

\section{Capital, Field, and Habitus}

The first foundational Bourdieusian concept is capital. Economic capital is a resource that can be exchanged for benefits or used as a means of influence. However, for Bourdieu, capital also comes in three additional forms - cultural, social, and symbolic. Cultural capital refers to the skills, knowledge, and dispositions that people gain during their life, the form of which depends on the interactions and experiences they have within society. ${ }^{28}$ Similarly, social capital refers to the social networks that people can draw upon for support during these interactions and

\footnotetext{
${ }^{24}$ Adrienne Barnett, Contact and Domestic Violence: The Ideological Divide, in Feminist Perspectives on ChILD LAW, supra note 6 , at $129,133$.

${ }^{25}$ Joanne Conaghan, Intersectionality and the Feminist Project, in INTERSECTIONALITY AND BEYOND, supra note 16, at 21.

${ }^{26} I d$. at 30 .

${ }^{27}$ A notable exception to this is the work of Hilary Sommerlad, who has productively drawn Bourdieusian theory into sociolegal research. See Hilary Sommerlad, Socio-Legal Studies and the Cultural Practice of Lawyering, in EXPLORING THE 'SOCIO' OF Socio-Legal Studies, supra note 12, at 205; Hilary Sommerlad, The "Social Magic" of Merit: Diversity, Equity and Inclusion in the English and Welsh Legal Profession, 83 Fordham L. Rev. 2325 (2015).

${ }^{28}$ Pierre Bourdieu, The Social Structures of the Economy 211 (2005).
} 
experiences. Therefore, both forms of capital are accumulated through life experiences - they differ according to the people that an individual has met and formed connections with, as well as what they have learned, been exposed to, and taken interests in throughout their lives. In practice, both function as tangible resources that can be exchanged or used to gain advantages in different contexts.

Symbolic capital, however, refers to things like authority, reputation, and prestige, which can easily be used to accrue other forms of capital. Education is an important example of symbolic capital because it is something that can be exchanged for other forms of valuable capital in a variety of different contexts. ${ }^{29}$ By distinguishing between these different kinds of resources, it is possible to understand how people from different social origins have different opportunities and possibilities available to them. However, rather than just signifying differences between people, the concept of capital can be used to expose the different value that is attributed to different kinds of capital within society.

This leads to Bourdieu's second concept: Field. Bourdieu argued that society is made up of several overlapping fields which all have their own practices and hierarchies of value. If capitals are synonymous with wealth, then fields are the marketplaces in which those capitals are spent and exchanged. Within each field, therefore, capitals are assigned value which determines how they can be used and the extent to which people can succeed in each context. In this sense, fields are sites of competition in which people struggle against each other in order to establish their "cultural competence" within any given arena. ${ }^{30}$ In other words, the capitals that are useful within one field may be completely different from those that are valuable in another. However, there are some kinds of capital—such as the skills and confidence that may come from a university education - which are valuable across several fields, but the opportunities to accumulate this kind of symbolic privilege are by no means evenly distributed. In practice, Bourdieu argues, there are overlaps between fields relating to law, politics, and economics, because the holders of symbolic capital across each of these fields have "kindred world views." ${ }^{31}$ In other words, those who hold power within society generally have a greater capacity to continually influence the shape and structure of official fields, and inevitably do so in their own interests.

In relation to law, Bourdieu extensively discussed that one way of doing this is by privileging unique practices and hierarchies that characterize the "juridical field." 32 Here, he explains that law is a field with its own underpinning set of protocols and assumptions, as well as its own internal social, psychological, and linguistic codes which all frame the way that law is practiced and negotiated but are never specifically recorded or acknowledged. ${ }^{33}$ For example, valued capitals in the juridical field include knowledge of and familiarity with legal rules, as well as specific ways of behaving and communicating which are perceived as authentic to law. These unique forms of cultural capital enable those who are initiated in law to "explore and exploit the range of possible rules and use them effectively as symbolic weapons to argue a case." ${ }^{34}$ Similarly, within the juridical field, certain forms of speech and written text have greater meaning and value than they do outside of this context. For example, when giving legal judgments, the act of speaking has the specific power of making something true. Additionally, the written formalization of text in a court document gives those words power in ways that would not be possible if they were simply said aloud. ${ }^{35}$ The value that is placed on juridical capital within the juridical field therefore has a distinctly exclusionary effect for those who have not been initiated through legal education and training. These exclusionary practices

\footnotetext{
${ }^{29}$ Pierre Bourdieu, The Force of Law: Towards a Sociology of the Juridical Field, 38 HastingS L.J. 805, 812 (1987).

${ }^{30}$ Pierre Bourdieu, Distinction 86-87 (1984).

${ }^{31}$ Bourdieu, supra note 29 , at 842 .

${ }^{32} I d$.

${ }^{33} \mathrm{Id}$. at 806 .

${ }^{34} I d$. at 827 .

${ }^{35} \mathrm{Id}$. at $809-10$.
} 
enable the juridical field to set its own cultural parameters of what is legally relevant and important, and to dismiss and devalue other skills and perspectives. ${ }^{36}$

Bourdieu's final concept is the habitus. The habitus is the internal mechanism through which people accumulate different kinds of capital and develop their own sense for which capitals are useful when they engage with different fields. This concept requires researchers to consider how people perceive the context in which they find themselves, and how their responses can in turn further shape their experiences. As Mike Savage explains, "it is one thing to point to growing economic inequalities, but we need to see how people themselves see these divisions." 37 An important benefit of exploring experiences through the habitus, therefore, was to gain an insight into the subjective ways Litigants in Person themselves perceived the processes of the family court in England and Wales.

Taken together, these three concepts provide a means of tracing the ways that structural inequality and different perspectives may be discounted within the legal system, because the authority and legitimacy of law is instead derived from the supposed objectivity of legal rules and practices. However, through Bourdieusian theory, it is possible to expose that this is by no means objective - rather, the juridical field operates to selectively recognize certain capitals, and to discount capitals that do not fit neatly into the structure of this field. For example, within my research, Bourdieusian theory was useful for exploring how Litigants in Person frequently experienced cultural forms of exclusion from decision-making during court hearings, due to specialist language that was used by legal professionals, or because they were unable to comply with highly specialized procedure such as advocacy or cross-examination. In other words, they were often unable to participate in the manner expected by those working in the juridical field, and as such, perceived the court as an environment in which they were powerless to influence the outcome of hearings. ${ }^{38}$ Bourdieusian concepts can therefore be used to compliment and reinforce the feminist objectives of exposing the hidden narratives of law, as well as the implications of law's blindness to inequality.

\section{An Intersectional Understanding of Inequality}

In relation to socio-economic inequality, these Bourdieusian concepts are extremely useful for understanding the important links between economic and cultural forms of subordination, and the implications of this for people who are attempting to participate in the juridical field. However, it is clear from feminist theory that economic inequality is not the only structural force that shapes experiences of law. Nancy Fraser argues, for instance, that although inherently linked with economic inequality, there are many other ways in which people can be oppressed or disadvantaged on the basis of who they are, and their status within other structures in society, like gender and race. ${ }^{39}$

Although Bourdieu did not explicitly discuss this, his concepts are flexible enough to provide an understanding of these other structures of inequality, because they account for the historical reiteration of both unequal outcomes and the processes by which these outcomes are produced. ${ }^{40}$ For example, the task of extending these concepts to address other forms of disadvantage has already been taken forward by a new generation of Bourdieusian sociologists in the UK. ${ }^{41}$ Approaching these concepts from very different academic backgrounds to Bourdieu, these

\footnotetext{
${ }^{36} I d$. at $828-29$.

${ }^{37}$ Mike Savage, Social Class in the 21st Century 1 (2015).

${ }^{38}$ Mant, supra note 3.

${ }^{39}$ Nancy Fraser, From Redistribution to Recognition? Dilemmas of Justice in a "Postsocial" Age, in AdDING INSULt TO Injury: Nancy Fraser Discusses Her Critics 9, 10-16 (Kevin Olson ed., 2008); Nancy Fraser, Fortunes of Feminism: From State-Managed Capitalism to Neoliberal Crisis 193-94 (2013).

${ }^{40}$ Hilary Sommerlad \& Peter Sanderson, Gender, Choice and Commitment: Women Solicitors in England and WALES AND THE STRUGGLE FOr EQUal STATUS 29, 37 (1998).

${ }^{41}$ Ciaran Burke et al., Introduction: The Development of Bourdieu's Intellectual Heritage in UK Sociology, in BOURDIEU: THE NeXt Generation 1 (Jenny Thatcher et al. eds., 2016).
} 
scholars have been able to develop concepts like "black cultural capital," and drawn links between the habitus and the concept of respectability in order to address the ways in which structures of value are racialized and gendered as well as classed. ${ }^{42}$

This means that it is possible to use these concepts in a way that is aligned with the feminist commitment to intersectionality. In relation to law, for instance, Hilary Sommerlad and Peter Sanderson use Bourdieusian theory to argue that the juridical field facilitates a culture that is specifically exclusionary to women. ${ }^{43}$ In their work, Sommerlad and Sanderson use the concept of field to demonstrate how legal rules are gender blind, and therefore do not account for structural constraints like caring responsibilities or other social arrangements which disproportionately affect women. As such, the inequality that women experience across society is constructed as irrelevant within the juridical field. ${ }^{44}$ Additionally, through the concept of capital, they explore the ways in which women can be ascribed certain characteristics based on their sex or gender, which are then devalued within the juridical field. In their work, characteristics associated with femininity or motherhood were ascribed to women by others in the field, and these were then undermined, misrecognized, and devalued in ways that those held by men were not. ${ }^{45}$ In this sense, Bourdieusian concepts can be used to understand how gender-based inequality can produce disadvantage which is different to the disadvantages which stem from socio-economic inequality, and that both of these structural inequalities can compound and intersect each other within the lived experiences of women.

Bourdieusian concepts can therefore be used to think through not only how different structures of inequality operate, but also be applied in an intersectional way, so as to gain an understanding of how categories like class and gender work together to produce unique experiences of disadvantage. A major benefit of doing this is that it enables analysis to move beyond talking about categories like gender, race, and class as if they are mutually exclusive. Instead, an intersectional application of Bourdieusian theory provides an imperative to "complicate our understanding of the social dynamics of inequality" by embracing the complex and overlapping ways in which these categories may operate. ${ }^{46}$ For example, within the context of this research, this meant I was able to recognize not only the cumulative ways in which Litigants in Person were affected by different structures of inequality, but also the unique and complicated ways in which they experienced disadvantage as a result of their different social positions.

Taken together, Bourdieu's concepts and feminist legal theory provide extremely useful and versatile tools which can be used to expose a rich understanding of how different structural inequalities may shape the experiences that people have of law, and how law operates to cut through these lived realities. However, they do not in themselves provide tools to understand how these inequalities may manifest as disadvantage within the legal system itself. Given that the purpose of this research was to understand the disadvantages that may be facilitated within this system, it was important to reinforce these structural tools with the third approach of ANT, which provides a materialist understanding of disadvantage within specific contexts.

\section{Actor-Network Theory}

Despite the word "theory" in its name, Actor-Network Theory is best understood as an analytical method that can be used to explore social arrangements, rather than a theory through which to

\footnotetext{
${ }^{42}$ Beverley Skeggs, Formations of Class and Gender: Becoming Respectable (1997); Nicola Rollock, Legitimizing Black Academic Failure: Deconstructing Staff Discourses on Academic Success, Appearance and Behaviour, 17 INT'L STUD. IN SocIo. OF EDUC. 275 (2007); Derron Wallace, Re-Interpreting Bourdieu, Belonging and Black Identities: Exploring 'Black' Cultural Capital Among Black Caribbean Youth in London, in Bourdieu: The NeXT Generation, supra note 41 , at 37.

${ }^{43}$ SOMMERLAD \& SANDERSON, supra note 40, at 17.

${ }^{44}$ Id. at 2 .

${ }^{45} \mathrm{Id}$. at $28-29,37-38$.

${ }^{46}$ Grabham et al., supra note 22 , at 13 .
} 
understand or explain them. This approach was developed within the field of science and technology studies and is commonly attributed to the work of Bruno Latour. ${ }^{47}$ Taking inspiration from the scientific tradition, ANT advocates examining social arrangements on a micro scale, and encourages researchers to consider how material objects and locations play important roles within those arrangements. ${ }^{48}$ Although ANT is still used by only a few scholars within socio-legal studies, ${ }^{49}$ it can be understood as part of a broader materialist turn within the discipline, which has emphasized the importance of recognizing that law is, in fact, inseparable from its physical conditions. ${ }^{50}$ The material reality of law has sometimes been neglected within approaches that focus more heavily on the cultural manifestations of law and society. ${ }^{51}$ While feminist theory and Bourdieusian theory are useful for asking questions about the structural context in which Litigants in Person are navigating the legal system, Actor-Network Theory is therefore useful for documenting the specific and material ways in which these experiences actually play out in the court process. However, because of its explicit focus on the micro-scale, there were also epistemological difficulties inherent in combining it with the other structural theories that comprised this framework. In this section, I will first outline the resources that this approach held for the research, before turning to reflect on how it was possible to reconcile this challenge and combine these three theories.

\section{The Actor-Network Theory Approach}

There are two central tenets of Actor-Network Theory. The first is that everyone and everything is both an actor within a network, and a network in itself. The second is that actors can be both human and non-human. The family court, for example, can be understood as one actor within the network of the legal system. However, if analytically useful, it can also be examined as a network that can be broken down into its own constituent actors: Litigants in Person, judges, lawyers, as well as courtrooms and paperwork. In turn, these actors can also be deconstructed and examined, and there is no limit to how far any object of analysis can be broken down into its constituent parts. This means it is possible to explore in detail the relationships between its actors, and specifically trace how certain actors are able to influence others and shape the network. While some actors may be able to translate the objectives of others into those that mirror their own, others may have difficulty negotiating some of these relationships. ${ }^{52}$ Therefore, Actor-Network Theory is extremely useful for unpacking exactly how people may face specific problems at various stages of filling out paperwork, navigating court buildings, and constructing legal arguments, where their success depends on their relationships with other actors. Taking an Actor-Network Theory approach to this project involved carefully documenting the interactions that Litigants in Person had with different aspects of the legal system and paying specific attention to the material detail of those interactions. For example, this enabled me to appreciate the difficulties that Litigants in Person faced as a result of how physical court environments were designed, such

\footnotetext{
${ }^{47}$ Bruno Latour, Reassembling the Social: An Introduction to Actor-Network-Theory (2005).

${ }^{48}$ John Law, After Method: Mess in Social Science Research (2004).

${ }^{49}$ Annelise Riles, The Network Inside Out (2000); David Cowan \& Helen Carr, Actor-Network Theory, Implementation, and the Private Landlord, 35 J.L. \& SoC'Y 149 (2008); Alain Pottage, The Materiality of What?, 39 J.L. \& SoC'Y 167 (2012); Emilie Cloatre, Pills for the Poorest: An Exploration of Trips and Access to Medication in Sub-Saharan Africa (2013); Emily Grabham, Brewing Legal times: Things, Form and the Enactment of Law (2016); Caroline Hunter, Solar Panels, Homeowners and Leases: The Lease as a Socio-Legal Object, in EXPLORING THE 'LEGAL' IN SOCIO-LEGAL STUDIES 137 (David Cowan \& Daniel Wincott eds., 2016).

${ }^{50}$ Marie-Andree Jacob, Matching Organs with Donors: Legality and Kinship in Transplants (2012); Andreas Philippopoulos-Mihalopoulos, Spatial Justice: Body, Lawscape, Atmosphere (2014); Nicole Graham, Margaret Davies \& Lee Godden, Broadening Law's Context: Materiality in Socio-Legal Research, 26 GrIfFITH L. ReV. 480 (2018).

${ }^{51}$ Margaret Davies, Law Unlimited: Materialism, Pluralism and Legal Theory 42 (2017).

${ }^{52}$ Helene Buzelin, Unexpected Allies: How Latour's Network Theory Could Compliment Bourdieusian Analyses in Translation Studies, 11 The Translator 193, 196-97 (2005).
} 
as feeling intimidated by lawyers in court waiting areas and feeling disparaged by the formal layout of courtrooms. ${ }^{53}$

In this sense, ANT is often described as "ethnographic," because it requires researchers to describe the material manifestations of social arrangements, as well as the detailed process by which social arrangements come to be. ${ }^{54}$ This commitment of ANT has been particularly useful for socio-legal researchers who are interested in unravelling how law operates within society. As I have highlighted through Bourdieusian theory, the legal system is often artificially conceived as an arena with its own culture, assumptions, codes, and practices. These all operate as internal sources of legitimacy for the juridical field but are never specifically recorded or acknowledged. ${ }^{55}$ Several scholars have already demonstrated the value of using ethnographic approaches in order to challenge these underpinning assumptions about how law is understood and experienced. ${ }^{56}$ However, it is this combination of an ethnographic commitment to detail with a particular attentiveness to materialism which distinguishes ANT from just "good ethnography," and made it a particularly useful tool for this project. ${ }^{57}$

The materialist focus of ANT means that it asks questions about how non-human actors can play important roles and have significant effects for social arrangements. For example, Annelise Riles has used ANT to explore the role that documents play within the legal system. ${ }^{58}$ Legal documents, she argues, have the power to foreclose important and contentious debates. A document can be used as a means of rendering complex discussions as "a matter of settled history," because the act of recording something in a document can never fully capture the oral discussions that took place to produce that document. In this sense, documents are artifacts of a prior struggle, which themselves provide sources of further authority which can be drawn upon at a later stage by those who were able to influence the record in the first place. ${ }^{59}$ By tracing the specific role of the document within law, therefore, Riles is able to disrupt our thinking about how law is able to function and reinforce itself. ${ }^{60}$

Focusing on the micro scale through ANT therefore also means having to re-engage with the very nature of law as a social category, discipline, institution, and label. Importantly, and in alignment with the criticisms of intersectionality, this ensures that the structures and processes of the legal system itself are subject to critical scrutiny. Rather than conceiving of law as something that is already made, ANT requires researchers to provide a detailed account of law in the making-how specific interactions and relationships work together to produce outcomes like disadvantage. ${ }^{61}$

\section{Combining Structural and Anti-Structural Approaches}

Taken together, the tenets of ANT require researchers to avoid taking social arrangements for granted, and instead to scrutinize the relationships that make those arrangements possible. In

\footnotetext{
${ }^{53}$ Mant, supra note 3.

${ }^{54}$ Emilie Cloatre, Law and ANT (and Its Kin): Possibilities, Challenges and Ways Forward, 45 J.L. \& Soc'y 646 (2018); Gianpaolo Baiocchi et al., Actor-Network Theory and the Ethnographic Imagination: An Exercise in Translation, 36 QuAlitative Socio. 323, 330 (2013).

${ }^{55}$ Bourdieu, supra note 28 , at 806 .

${ }^{56}$ An important example is legal consciousness scholarship. See Patricia EWick \& Susan Sibley, The Common Place of LAW (1998).

${ }^{57}$ Cloatre, supra note 54 , at 659.

${ }^{58}$ Annelise Riles, Documents: Artifacts of Modern KnOwledge (2006).

${ }^{59} \mathrm{Id}$. at $76-78,83$.

${ }^{60}$ This is further reinforced by the work of other scholars who focus more generally on spatial and temporal dimensions of law. See Marie-Andree Jacob, The Strikethrough: An Approach to Regulatory Writing and Professional Discipline, 37 LEGAL Stud. 137 (2017); Linda Mulcahy, Legal Architecture: Justice, Due Process and the Place of Law (2010); Emily Grabham, Legal Form and Temporal Rationalities in UK Work-life Balance Law, 29 AUSTRALIAN FeminIST STUD. 67 (2014).

${ }^{61}$ Cloatre, supra note 54, at 657-58; Ron Levi \& Mariana Valverde, Studying Law by Association: Bruno Latour Goes to the Conseil d'Etat, 33 L. \& SOC. INQUIRY 805, 822 (2008).
} 
a way that clearly overlaps with feminist objectives, ANT is underpinned by a bottom-up approach to understanding the complexity of social arrangements. However, by advocating that social arrangements should be examined in a purely empirical way, ANT is epistemologically and ontologically distinct from the other theories in this framework. While feminist legal theory and Bourdieusian theory each provide different resources for understanding how disadvantage may relate to structural inequality and difference, ANT has traditionally been critical of these kinds of theoretical explanations. For Actor-Network theorists, using social theory to frame research findings is to take a shortcut - to treat inequality as an explanation for disadvantage, rather than to see disadvantage an effect of a social arrangement that needs to be explored. ${ }^{62}$ It was on this basis that Latour originally went so far as to argue that social theory such as Bourdieusian theory should be "jettisoned." 63

Therefore, these were two contesting assumptions and worldviews that I needed to reconcile in order to draw these theories together into a theoretical framework that I could use within my research. On the one hand, ANT raises an important concern about the usefulness of social theory for understanding how people experience law. For instance, it would have been particularly detrimental to the aims of my project if I were to use theory in a way that simply reiterated theoretical presumptions and failed to extend current understandings or incorporate first-hand experiences of law. However, on the other hand, while this is an important criticism of how researchers may use theory, this also exposes a key weakness of the ANT approach. By advocating a flat ontology in which researchers may only explore what they find during their empirical investigations, ANT does not pay attention to the deeper and historically reiterated structures of inequality that provide the context within which these social practices unfold. In this sense, ANT may be interpreted as rejecting analyses that account for categories such as gender or class, or the historical dimensions of these structures. This skepticism of social theory has been heavily criticized. Feminist scholars in particular have argued that without a theoretical understanding of the ways in which macro structures and categories have historically reiterated arrangements of inequality, it is impossible to fully understand the relationships and interactions which take place on a micro scale. ${ }^{64}$

By focusing only on the interactions that happen on the ground, ANT risks being "an apolitical strategy that effectively effaces the violent histories and embedded power imbalances that constitute social relations." ${ }^{\prime 5}$ In other words, while ANT theorists may criticize structural approaches for explaining without describing, ANT is also at risk of describing without explaining. ${ }^{66}$ The task of drawing ANT into this theoretical framework was therefore a significant challenge, given that its underpinning assumptions and worldview risk reiterating a problematic blindness to structural arrangements of inequality. However, by working through this tension, I concluded that it is possible to use ANT in a way that is sensitive to this structural context for two reasons.

First, it is possible to use Actor-Network Theory without adhering to anti-structuralism. Reconciling an anti-structuralist approach with structural approaches is by no means simple, but it is still possible to use these approaches concurrently by following the example of other scholars who have explicitly rejected the anti-structuralist ontology that underpins traditional ANT approaches. As ANT has been applied in multiple disciplines, researchers have confronted these important "blind spots," and instead recommended using ANT Theory as a set of sensibilities that can be used more productively than traditional applications of Latourian ANT. For example, within law, Emilie Cloatre has most prominently mitigated these blind spots by taking the benefits of ANT's micro approach, whilst rejecting ANT's skepticism of structural theory. She argues that it is instead far more progressive to draw ANT together into theoretical frameworks with other

\footnotetext{
${ }^{62}$ Baiocchi et al., supra note 54 , at 336.

${ }^{63}$ LATOUR, supra note 47.

${ }^{64}$ Cloatre, supra note 54 .

${ }^{65} \mathrm{Id}$. at 653.

${ }^{66}$ Levi \& Valverde, supra note 61 , at 822.
} 
theories that provide a proper account of how power and inequality operate on a structural scale. ${ }^{67}$ In doing so, Latour's view of social theory has often been resigned to classical or purist forms of ANT, and is generally regarded as at best problematic, and at worst dangerous. ${ }^{68}$

Second, rejecting anti-structuralism does not mean that ANT's concerns about theory are discounted. Instead of jettisoning theory, researchers are encouraged instead to use ANT as a broad set of sensibilities that can be used as pragmatic guides through which to orient social theory. ${ }^{69}$ Cloatre has described this method of using ANT "as a matter of care." ${ }^{\text {" }}$ As discussed so far in this section, these sensibilities include an attentiveness to the relational and material nature of social arrangements, as well as how particular social arrangements come to produce effects like disadvantage. ${ }^{71}$ By using ANT in this way, it is possible to move beyond using inequality or disadvantage as explanations for the social phenomena being studied, and instead commit to explaining how arrangements of disadvantage or inequality come to be, through a renewed attention to the micro-connections that form these arrangements. ${ }^{72}$ Although it is unlikely that he would have embraced ANT, Bourdieu himself actually advocated the idea that researchers should be open to different approaches. He recommends, for instance, that researchers should "mobilise all the techniques that are relevant and practically useable, given the definition of the object." 73 Similarly, as discussed earlier, the field of sociology within the UK includes an emerging generation of Bourdieusian scholars who are committed to developing and refining Bourdieu's concepts beyond their original incarnation as a grand theory of society. Will Atkinson, for instance, explains that this task involves working with and against Bourdieu, and that researchers should not be afraid of deviating from him when the research demands it. ${ }^{74}$

Instead of undermining the structural understandings gained from the other theories, it is therefore possible to use ANT as a resource for asking more questions about how disadvantage is experienced on the ground, rather than closing down questions about how that disadvantage is rooted in broader structures of inequality. In this sense, ANT — used as a sensibility — can be used in a way that actually elevates feminist concerns and objectives, because it indicates that researchers need to remain open to experiences which do not fit with pre-existing ideas that underpin structural theories. Even more importantly, ANT can be used in a way that holds researchers accountable to using theory in a way that helps to gain a deeper understanding of the experiences that people have of law.

\section{E. Working Politically: The Benefits of Tension}

These three approaches draw different conceptual resources from distinct schools of thought. Taken together, they provide the tools to understand how people are positioned differently within society, how this may shape specific forms of disadvantage, and how this plays out on a material level within the legal system in England and Wales. Combining these tools was by no means a simple task - there are several moving parts that work together and contradict each other in different ways. Most notably, there was an important conflict between the underpinning assumptions of ANT, and the other two approaches. While ANT suggests that knowledge should be empirically driven and researchers should avoid using concepts like inequality as explanations for social

\footnotetext{
${ }^{67}$ Cloatre, supra note 54 , at 660 .

${ }^{68}$ Levi \& Valverde, supra note 61, at 811; Cloatre, supra note 54, at 653, 658.

${ }^{69}$ John Law \& Vicky Singleton, ANT and Politics: Working In and On the World, 36 QUALITATIVE Socio. 485, 485-86 (2013).

${ }^{70}$ Cloatre, supra note 54 , at $660-61$.

${ }^{71}$ Baiocchi et al., supra note 54, at 335.

${ }^{72}$ Cloatre, supra note 54 , at 653 .

${ }^{73}$ Pierre Bourdieu \& Loic Wacquant, An Invitation to Reflexive Sociology 227 (1992).

${ }^{74}$ Will Atkinson, From Sociological Fictions to Social Fictions: Some Bourdieusian Reflections on the Concepts of 'Institutional Habitus' and 'Family Habitus,' 32 BRITISH J. Soc. \& EDUC. 331, 344 (2011).
} 
phenomena, feminist theory and Bourdieusian theory suggest that empirical findings cannot be properly understood without a theoretical understanding of the structural context in which they occur. In order to draw these theories together within my research, therefore, I had to make a political decision to reject the anti-structural premises of ANT, and instead conceptualize this approach simply as a sensibility. On the basis of this, I will now argue that the task of combining different theoretical approaches is frequently political, because researchers must consider how their theoretical choices affect not only their own research, but also how they may contest, expand, or develop the dominant assumptions and worldviews that characterize socio-legal scholarly traditions.

When combining approaches from different schools of thought, scholars are required to engage critically with each of their selected approaches, because they are forced to reflect on how these conceptual resources fit together and how they may contradict each other. Within the context of their own projects, this means that researchers have to distinguish between the contributions of different approaches and identify those that are valid within the context of the specific research questions at hand. However, when theories are underpinned by different epistemological or ontological assumptions, researchers will inevitably have to engage in what Davies calls a "politics of definition." This occurs when two or more theoretical objects come into contact conceptually or physically, and cannot be reduced to a single form, thus leading to a clash of ideas and objectives. It is at this point that researchers must decide how to proceed, and are forced to apply a politics of definition, through which one set of assumptions is empowered or prioritized, and the others are marginalized. ${ }^{75}$

Within the context of this project, for instance, the contradictions between the structural and anti-structural assumptions that underpinned these theories arose repeatedly, and as a result, the research process was characterized by a set of inherent and unrelenting tensions which frequently had to be confronted and reconciled at various key points of fieldwork and analysis. This task may be particularly difficult for researchers trained in certain scholarly traditions. For example, before undertaking this project, I had more experience working with traditional sociological approaches like Bourdieusian theory than with approaches like ANT. I was therefore conscious of the risk that I would favor Bourdieusian explanations of disadvantage in my analysis instead of taking the time to also explore these social arrangements through ANT. In order to contend with these clashes, I would continually revisit my own analysis and ensure that I was not using Bourdieusian concepts as explanatory tools, but rather employing them as tools with which to sensitize myself to wider structures, in light of the sensibilities I had drawn from ANT. The research process was by no means linear or comfortable but left me with a sense that I had been rigorous, careful, and attentive. It is understandable and common for researchers to shy away from this kind of challenge. As Davies explains, within the discipline of law, there is a deep-running preference for an "aesthetic of coherence." 76 Arguments and findings are naturally more convincing if they present logical conclusions and do not draw attention to other elements that do not quite fit. But, she argues, there is "no logical reason for theory to insist upon purity and neatness, especially if it means excluding or foreclosing the intrinsic complexity of its objects ...."77

Building upon this, I argue that engaging in this political task is particularly important for early career scholars because these decisions about which assumptions and worldviews to reiterate or resist are not only political within the context of individual research projects, but also hold broader political consequences for the socio-legal discipline. The research that is produced as a result of theoretical choices such as those outlined above, has the potential to contest, expand, or develop existing narratives about what the world is like, how it should be studied, and whose voices and experiences should be relied upon when building an account of social phenomena. Legal theory in

\footnotetext{
${ }^{75}$ DAVIES, supra note 51 , at $10-11$.

${ }^{76} I d$. at 4 .

${ }^{77} I$. at 5.
} 
particular is historically rooted in works that reflect the perspectives of a narrow demographic, and it is therefore imperative for researchers to reflect upon how their theoretical choices may influence the kinds of narratives that govern socio-legal research.

This kind of reflexivity aligns with a key objective of feminist research, which is to pay due care to the way that dominant narratives may easily be reiterated within research that appeals to existing structures of legitimacy, and to instead create the space for oppositional meanings to emerge. ${ }^{78}$ For example, Fraser has written extensively about the need for research to not only ask questions about inequalities of distribution or recognition within society, but also to pose important challenges to the ways in which particular voices are represented within the political process of determining the particular arrangements by which distribution or recognition occurs in the first place. ${ }^{79}$ Fundamentally, this involves acknowledging the constructed nature of knowledge, and recognizing that forms of oppression can be rendered invisible not only by dominant structures of power, but also by the efforts of researchers who attempt to address these structures. ${ }^{80}$ When combining multiple theories, therefore, researchers should take this idea forward in order to work politically, by empowering or prioritizing epistemological assumptions that expand the scope of dominant ideas and narratives, and marginalizing those that close down opportunities for deeper and more meaningful understandings. At a fundamental level, this means that when scholars combine different theoretical tools, they can work politically by asking questions such as: What kind of knowledge are they likely to produce as a result of using certain social theories? How might this knowledge contribute, resist, or reiterate existing power dynamics or structures of inequality?

If done thoughtfully and with care, therefore, working politically to combine different approaches can open researchers up to broader analytical possibilities. For example, working through this tension enabled me to use very different theoretical tools simultaneously in order to oscillate between macro and micro scales of analysis. In turn, this meant that it was possible for me to acknowledge both the broader historical significance of structural inequalities, whilst also remaining mindful as to the need to empirically explore how these inequalities actually manifest within material and everyday experiences. This sort of analytical flexibility can be extremely valuable in socio-legal projects. For example, in relation to her three conceptions of injustice, Fraser also distinguishes between different kinds of remedies that can be proposed within research. On the one hand, she argues that there are "affirmative" remedies, which attempt to redress inequality by improving current social arrangements-such as by redistributing resources or revaluing previously devalued identities within particular contexts. ${ }^{81}$ On the other hand, there are "transformative" remedies which attempt to destabilize the assumed differentiations that exist between different social groups and transform the very basis upon which these resources are distributed or valued. ${ }^{82}$ It is tempting, especially within the UK where a greater amount of socio-legal research is premised upon empirical work, to pay greater attention to affirmative remedies. This may often be a rational decision, as it is this work which is likely to have more immediate influence. For example, in this project it was possible to use ANT to reflect on how small changes to the court process, such as rearranging courtroom furniture or changing the order in which people spoke in the courtroom, could make a difference to many experiences of disadvantage that are currently unfolding in the legal system in England and Wales. However, by combining this with feminist theory and Bourdieusian theory, it was possible to produce research findings which also gave an insight into how arrangements within this legal system need to be transformed on a broader scale, in ways that account for the structural inequalities which characterize society as a whole and play an important role in these relationships.

\footnotetext{
${ }^{78}$ Bartlett, supra note 15, at 857; Barnett, supra note 24, at 132.

${ }^{79}$ Fraser, ForTunEs OF FEMINISM, supra note 39.

${ }^{80}$ Bartlett, supra note 15 , at 848 .

${ }^{81}$ Fraser, From Redistribution to Recognition?, supra note 39.

${ }^{82} I d$.
} 
Inevitably, the ways in which scholars make theoretical choices are likely to be influenced by the context in which they are trained. In the introduction to this Special Issue, the authors discussed how the different scholarly traditions between Germany and the UK have emerged as a result of different patterns of scholarship, pedagogical practices, and institutional structures. From the articles in this Special Issue, it appears that these differences have played an important role in shaping how early-career scholars across these jurisdictions conceptualize the possibilities of socio-legal studies. In the UK, for example, a growing interest in socio-legal research also facilitated greater retrospection among socio-legal scholars about how this scholarship might be used to inform university legal education. ${ }^{83}$ As such, the pedagogical influences of socio-legal research can be seen even at the undergraduate level of legal study. This is reinforced by the existence of institutional and national research council funding opportunities for students to embark upon socio-legal doctoral projects, which are extremely competitive but often come with integrated training pathways for research methods. Socio-legal doctoral candidates also often have the benefit of both inter- and intra-institutional training and financial support. The Socio-Legal Studies Association, for instance, is a charitable organization which plays an important role in facilitating a socio-legal community of scholars within the UK by holding annual conferences, funding competitions for research grants, and sponsoring events which contribute to their aim of advancing education, research, teaching, and knowledge in socio-legal studies. ${ }^{84}$ As part of their work, this includes dedicated training opportunities, workshops, and funding opportunities for postgraduate and early-career members. In recent years, the organization has seen a significant increase in the proportion of doctoral candidates within their membership, which is indicative of the structural support that exists for socio-legal early-career researchers in the UK.

As one of these early-career scholars, it is inevitable that my own attitude towards research has been significantly shaped by this fertile environment of training and supervision. The work of leading socio-legal scholars, as well as the support of the UK socio-legal community, significantly influenced my experience of legal education and doctoral study in England and Wales, and they continue to inform the teaching and research that I do through my own academic position. Earlycareer scholars in the UK are therefore less likely than those in other countries to face barriers to establishing the value of taking an interdisciplinary approach to studying law. However, the choices that they make about how to build upon the work of more senior scholars have important implications for which scholarly traditions are strengthened and reiterated, and how the discipline is to continue to develop. In this Article, I have argued that early-career scholars may choose to combine approaches from different schools of thought within socio-legal studies. This activity of merging theory can be inherently critical simply by reflecting on the implications of research that relies upon particular conceptions, such as the legitimacy it may lend to particular views of the world. In this sense, Davies advocates the metaphor of "pathfinding" as a means for researchers to begin navigating theory in a way that adds further dimensions to existing patterns of legal thought. ${ }^{85}$ By following existing paths, or forging new paths, we reinforce and ultimately reimagine different understandings of law and its place within society. ${ }^{86}$ By this, she means that theory is not only useful for understanding existing social arrangements, but also for producing alternative imaginings of what these arrangements should be like. The conceptual and analytical choices we make therefore have important consequences, because " ... drawing out aspects of the present that appear to provide direction for the future, and intensifying them theoretically, prefigures a world that is commensurable with the present and past, but which perhaps adds additional

\footnotetext{
${ }^{83}$ Fiona Cownie \& Anthony Bradney, An Examined Life: Research into University Legal Education in the United Kingdom and the Journal of Law and Society, 44 J.L. \& Soc'y 129, 137-38 (2017).

${ }^{84}$ See Welcome to the SLSA: Socia-Legal Studies Association, https://www.slsa.ac.uk/.

${ }^{85}$ DAVIES, supra note 51 , at $143-53$.

${ }^{86} \mathrm{Id}$. at $150-51$.
} 
emphasis to those elements of it worth promoting." 87 The task of combining theories can therefore in practice be an extremely productive exercise for the discipline because socio-legal scholars may be both empowered to find unanticipated potential within their research projects and enabled to embrace the political potential of the work they do with theory.

\section{F. Conclusion}

At the beginning of this Article, I stated that early-career socio-legal scholars are now faced with important choices about which theoretical, conceptual, and methodological tools they wish to employ within their research, and how they should do so. Inevitably, these choices have important implications for how socio-legal scholarship continues to grow and develop. In this Article, I have provided a reflection on my own experience of combining different socio-legal tools, in order to demonstrate the important value of merging approaches in a way that is both critical and attentive to these political possibilities. In doing so, I have outlined the difficulties and tensions that characterized the combination of feminist legal theory, Bourdieusian theory, and ANT. But there are likely to be a wide range of other complexities that come with combining other approaches. Further, it may not always be possible to reconcile underpinning contradictions between various approaches, especially those from very different traditions and disciplines. Nevertheless, this Article has demonstrated that there is value to be derived from attempting to work through these tensions. When undertaken with care and reflexivity, the task of combining socio-legal tools can be an opportunity for scholars to work politically by reflecting on how their theoretical choices affect not only their own understanding of social phenomena, but also make an important contribution to the task of contesting and expanding upon the dominant assumptions and worldviews that characterize scholarly traditions. This reflexivity is particularly imperative among early career scholars who choose to combine multiple theories, because the work of these scholars will shape the future assumptions and worldviews that characterize the socio-legal discipline.

\footnotetext{
${ }^{87} I d$. at 17.
} 